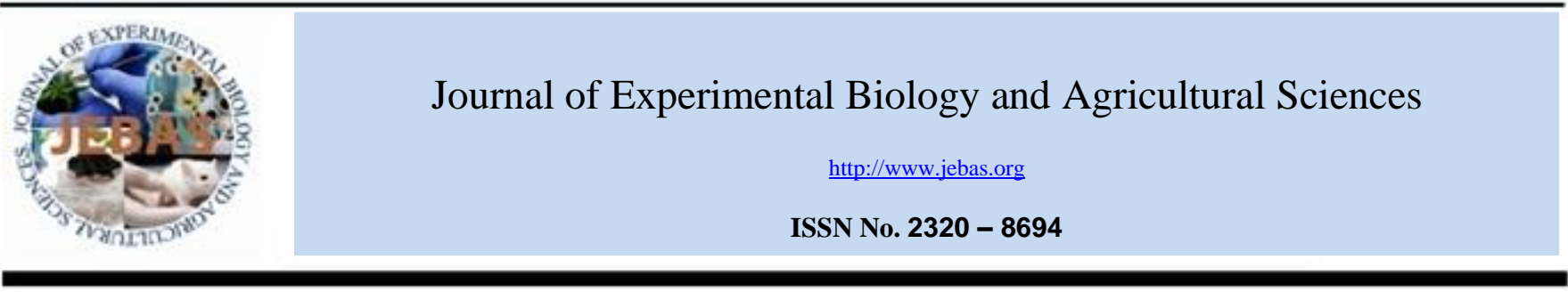

\title{
THE CLINICAL SIGNIFICANCE OF THE COMBINATION OF PATHOGENIC THERAPY IN CHILDREN WITH OVERACTIVE BLADDER SYNDROME (OAB) AND NOCTURIA
}

\author{
Morozov S L ${ }^{1}$, Guseva $\mathrm{N} \mathrm{B}^{2, *}$, Dlin V V ${ }^{3}$ and Tonkikh E V ${ }^{4}$ \\ ${ }^{1}$ Scientific assistant, Department of Nephrology, Pirogov Russian National Research Medical, 125412 Taldomskaya str 2, Moscow, Russia \\ ${ }^{2}$ Professor, Head of Moscow Voiding Dysfunction Centre, Speransky Pediatric Hospital, Pirogov Russian National Research Medical University, The Russian \\ representative ICCS, 123317 Shmitovsky pr. 29, Moscow, Russia \\ ${ }^{3}$ Professor, Head of the Department of Nephrology, Pirogov Russian National Research Medical University, 125412 Taldomskaya str 2, Moscow, Russia \\ ${ }^{4}$ Department of Clinical Pharmacology, Burdenko Voronezh Medical Academy, 394005 Studencheskaya street, 10, Moscow, Russia
}

Received - January 08, 2016; Revision - February 10, 2016; Accepted - April 25, 2016

Available Online - June 25, 2016

DOI: http://dx.doi.org/10.18006/2016.4(4).384.388

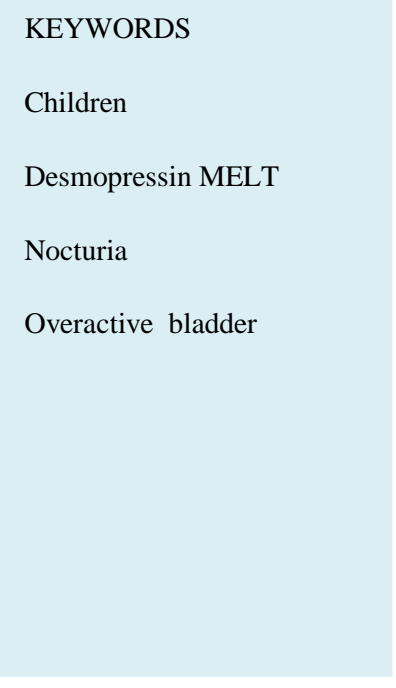

\begin{abstract}
The aim of the present study was to identify the frequency of nocturnal polyuria in children with suffering by $\mathrm{OAB}$. Further, efficacy of the oxybutynine monotherapy either individually or in combination with desmopressin MELT was also accessed in present study. In present study, total 150 patients were selected for the clinical trial at Moscow Voiding Disfunction Centre from 2007-2011. Data collected for this study were based on the intensity of urination, calendar of episodes of incontinence, results of dyuresis, uroflowmethry with determination of volume of residual urine, ultrasound examination (USE) of the kidneys and bladder. Among the examined 150 patients, only 50 respondents found suitable for the study while the rest 100 respondents were excluded from the study due to different reasons. These participants with clinical symptoms of urinary disorders were assessed by qualimetry and evaluated with $32 \pm 2.5$ points and were randomized into two treatment groups, among these group 1 (20 patients) were treated by oxybutynine and desmopress in MELT bedtime while the group 2 (30 patients) were treated by only basic therapy with oxybutynine. In group 1, the clinical picture is changed and the assessment of quality control has decreased towards the relief of clinical symptoms up to 22 points, on the basis of increasing the volume of the bladder and decrease nocturnal polyuria. This improvement is statistically significant reduction in the level of nocturia and $38 \pm 8 \%$ in
\end{abstract}

* Corresponding author

E-mail: guseva-n-b@yandex.ru (N.B. Guseva)

Peer review under responsibility of Journal of Experimental Biology and Agricultural Sciences.

Production and Hosting by Horizon Publisher India [HPI] (http://www.horizonpublisherindia.in/).

All rights reserved.
All the article published by Journal of Experimental Biology and Agricultural Sciences is licensed under a Creative Commons Attribution-NonCommercial 4.0 International License Based on a work at www.jebas.org.

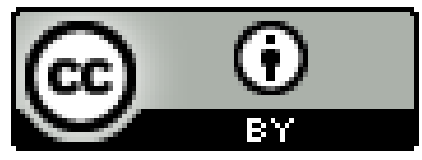


comparison with 24 hours in diuresis. The increase in the effective volume of the bladder was $31 \%$. While in case of group 2, although a improvement in the clinical symptoms was reported ( $27 \pm 2.5$ points), and this difference was statistically significant as compared to baseline values but it is least performing treatment as compared group 1. Further, in this group, the parameters of nocturnal polyuria also not changed. Thus, it was concluded that in the imperative syndrome and nocturnal polyuria can be affectively treated by integrated application oxybutynine and desmopressin MELT.

\section{Introduction}

Overactive bladder $(\mathrm{OAB})$ is a common disease in children over 5 years of age. Abrams et al. (2003) diagnosed OAB in $17 \%$ of the Northern Europe children aged between 5-12 years aged. Still etiology and pathogenesis of OAB have not been completely studied; nevertheless it was found that $\mathrm{OAB}$ may be a consequence of both neurogenic and non-neurogenic lesions (Bauer, 2002; Vishnevsky, 2005). With respect to multifactorial pathogenetic mechanism (morphofunctional immaturity, suppression of the vegetative nervous system, deficit of regional bloodsupply), the $\mathrm{OAB}$ syndrome in children is a polyetiological disease. The symptoms of OAB are urgent urination, imperative urinary incontinence and nocturia (Vishnevsky et al., 2001; Dreiper \& Smit, 2007). Nocturia is symptomized by controlled (leading to wakening) or uncontrolled (during sleep) urination two and more times during night (Vishnevsky et al., 2007). The key factors of this pathological symptom which considerably reduces quality of life of the patient are nocturnal polyuria and insufficiency of the reservoir function of the bladder. Nocturnal polyuria in combination with a small volume of the bladder creates a stable "conflict situation". The essence of the conflict is a disorder of equilibrium between intensity of production of urine and the ability of the bladder to accumulate urine at night hours. In these cases, diuresis at night exceeds the functional capacity of the bladder that in principle changes the habitual course of the process of urine excretion at the level of the lower portion of the urinary tract provokes frequent urinations at night (Glazener \& Evans, 2000).

Taking into consideration immaturity of vegetative regulation of the function of the lower urinary tract in children due to non-uniform development of organs and structures in the process of growth, multiple night-time, and bladder emptying is of the uncontrolled character. Recently this phenomenon was unambiguously qualified by using the term "enuresis". However, disorders at the "receptor/detrusor" level should be regarded in terms of the OAB pathogenesis. The ability of the detrusor to respond adequately to nerve impulse is possible only under the condition of normal energy provision (bioenergetics) of the smooth muscle structures (Nijman, 2004). Information regarding the treatment of patient suffering from $\mathrm{OAB}$ and nocturnal polyuria combindly are in scarcity; therefore present study was carried to investigate the frequency of nocturnal polyuria with $\mathrm{OAB}$ in children and to highlight the focus group study results of treatment with the oxybutynine monotherapy and combined treatment of oxybutynine and desmopressin MELT.

\section{Materials and methods}

For this study total 16578 patients with the OAB syndrome were examined at the Moscow Voiding Disfunction Centre from 2007-2011. Among the total examined patient, almost forty percent (6458 patient) showed the symptoms of nocturnal polyuria (nocturia), among these maximum had two and more episodes of enuresis per night. From this high frequency, total 150 respondents with $\mathrm{OAB}$ and nocturnal polyuria were selected for the three months study, this selection was primarily based on the combination of $\mathrm{OAB}$ and nocturnal polyuria and secondarily on the availability for the study. Respondents those who are not reside in Moscow are excluded from the study. The protocol of the study included the intensity of urination, calendar of episodes of incontinence, results of dyuresis, uroflowmethry with determination of volume of residual urine, ultrasound examination (USE) of the kidneys and bladder. Among the examined 150 patients, 88 (58\%) children had only imperative syndrome while 60 (40\%) children had both the imperative syndrome and night polyuria. Further, among the suffering respondents (60), 10 girls in particular, needed treatment for lower urinary tract infections were excluded from the study while the rest 50 study participants with clinical symptoms of urinary disorders were assessed by qualimetry and evaluated with $32+2.5$ points. Patients were randomized into two treatment groups. Patients in Group 1, consisted 20 children were treated by oxybutynine and desmopress in MELT bed time while Group 2 consisted of 30 patients who received only basic therapy with oxybutynine. Monitoring carried out up to 3 months of treatment.

Prescribed doses of oxybutynin (Driptan $5 \mathrm{mg}$ ) used in this study are varies with the age group and it was prescribed $1 / 2$ tablet 2 times in a day for children up to 7 years, while for the children of 8-11 years age group, same dose increased up to 3 times in a day. Further, for the children of the age group 12-14 years, one tablet 2 times in a day was prescribed and the same dose increased up to three times in a day for the children above 15 years. The design of the study corresponded to the level of conclusiveness 2(B), that is, the randomized, controlled study, in which the statistical analysis is made on the basis of the data of a small number of patients (not more than 50), has been conducted (Raes et al., 2006). 


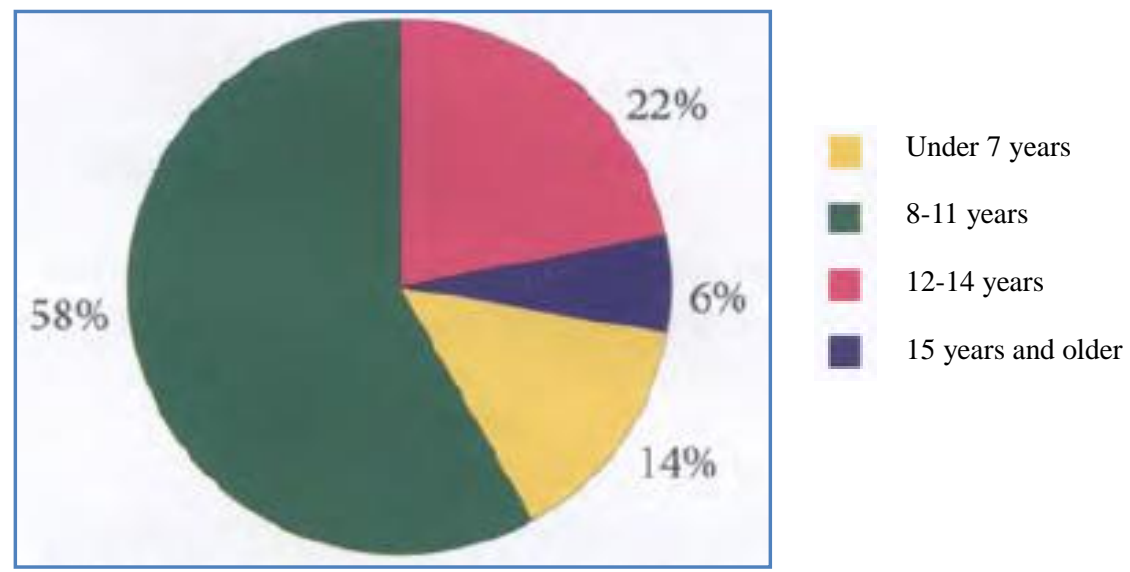

Figure 1 Distribution of patients with night polyuria by age groups.

The statistical processing of the results of this thorough investigation was conducted by using the methods of descriptive statistics and calculation of confidence intervals. The nominal level of significance was at $=0.05$. The check of statistical hypotheses was performed by using the methods of non-parametric statistics by hypothesis of uniformity of mathematical expectations for independent samples (groups) was checked by the Kramer-Welch's test (Sureshkumar et al., 2003).

\section{Results and Discussion}

By means of the data of the statistical instruments the baseline uniformity of clinical signs of urination disorders in patients of both groups was proved. The distribution of patients by age is presented in figure 1 and figure 2 .
In group 1 , the clinical picture is changing through increased urination in one portion and reducing the volume of nocturnal diuresis. Evaluation method of quality control was reduced from 32 to $22 \pm 2.5$ points. This was a statistically significant improvement in a decrease in volume of nocturnal diuresis to $38 \pm 8 \%$ compared with the total volume of urine output during the day. Further, treatment increasing the effective bladder capacity was $31 \%$.

In group 2, evaluation of clinical symptoms of urinary disorders has improved to $27 \pm 2.5$ points, which was statistically significant compared to baseline values. But the improvement was only from micturition volume in one portion as in Group 1 at $31 \%$. But the parameters of nocturnal polyuria have not changed. Thus, it was found that in the presence of an imperative syndrome and nocturnal polyuria best results were obtained when the complex and use of oxybutynin desmopressin MELT than only with oxybutynin alone.

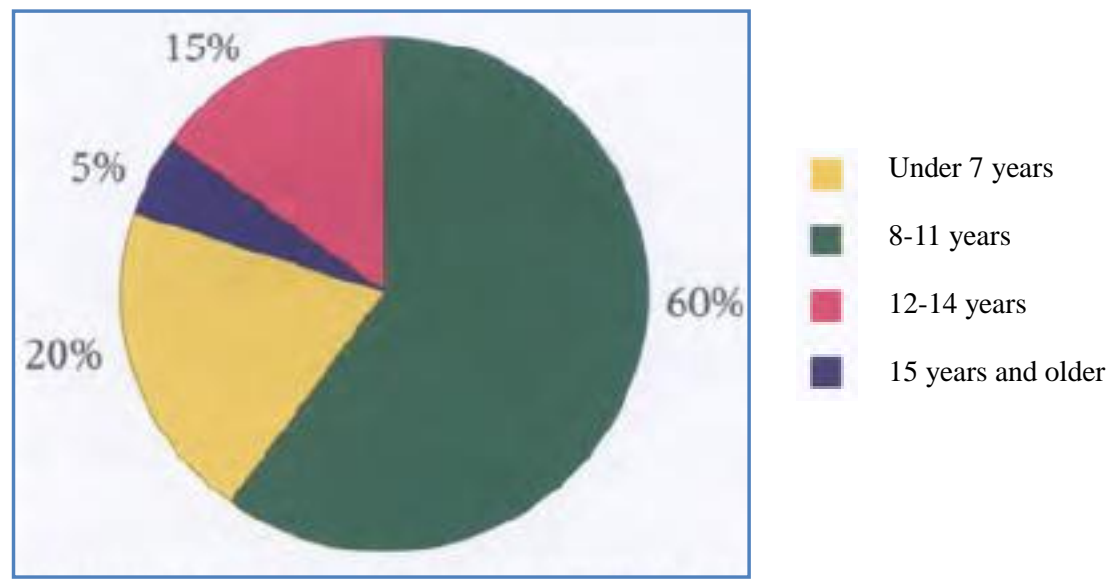

Figure 2 Age ranges in group 1 (20 patients). 


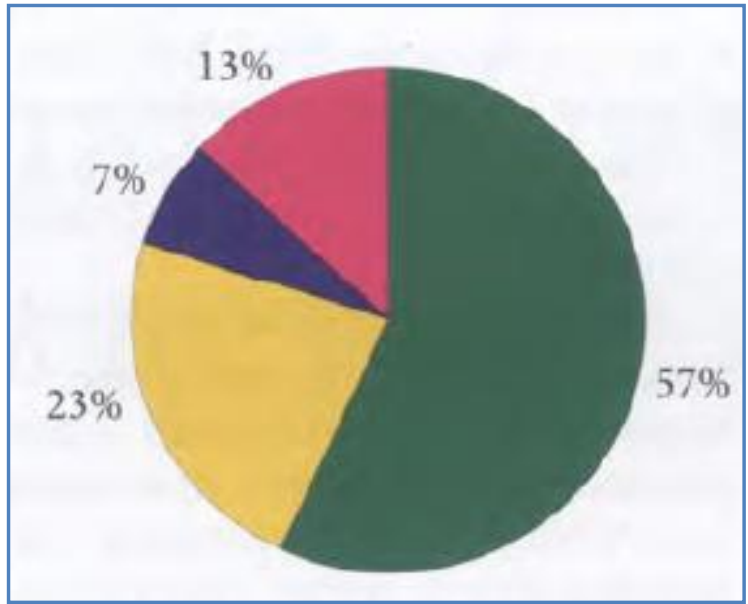

Under 7 years

8-11 years

$12-14$ years

15 years and older

Figure 3 Age ranges in group 2 (30 patients).

In group 1, combined treatment with desmopressin MELT was an increase in the gaps without enuresis episodes during the week. If the original aspect ratio of "wet" and "dry" nights in both groups was 6: 1, then after 3 months of treatment in group 1 ratio was 2: 5. In group 2, the ratio was 5: 3 . The ratio of "dry" and "wet" nights was used as a measure of the effectiveness of treatment after the first month and the indication to increase the dose of desmopressin MELT individually. In group 1, the use of desmopressin MELT in all children was started with a dose of $60 \mathrm{mg}$ (1 tablet). However, this dose was doubled $(120 \mathrm{mg})$ after 1 month of treatment in children in age group of 8-11 years. In groups of over 12 years as it was necessary to increase the initial dose of $120 \mathrm{mg}$ after 1 month of use. The dose was increased to $180 \mathrm{mg}$ in 5 patients.

Group 2 patients (age aspects shown in Fig. 3) were treated according to standard procedure oxybutynine ICCS at the same dosage, which is used in the 1st group. Doses were assigned depending on age. Side effects associated with the use of oxybutynine in the form of dry mucous membranes, was observed in only one patient.

The most interesting to us is the analysis of changes in clinical symptoms. Table Wisniewski for evaluation of clinical siptomy includes 5 sections, each of which contains characteristic 1) urge to urinate, 2) the quality of urinary incontinence, 3) nocturnal enuresis, and 4) the amount of urination per day and the volume of 1 portsii5) nocturnal urine volume. Patients in Group 1 score in the symptoms scores changed due to the decline in nocturnal polyuria and increase the effective volume of the bladder. Patients in Group 2 also increased the amount of urination portion, but the state remained the same nocturnal polyuria. When monitoring the effectiveness of treatment of patients in group 2 at 1 month assessment has changed due to the increased volume of the bladder urine (25-26 points), but the overall result was not statistically significant, due to the inability to provide a reduction in the frequency of enuresis episodes per night.

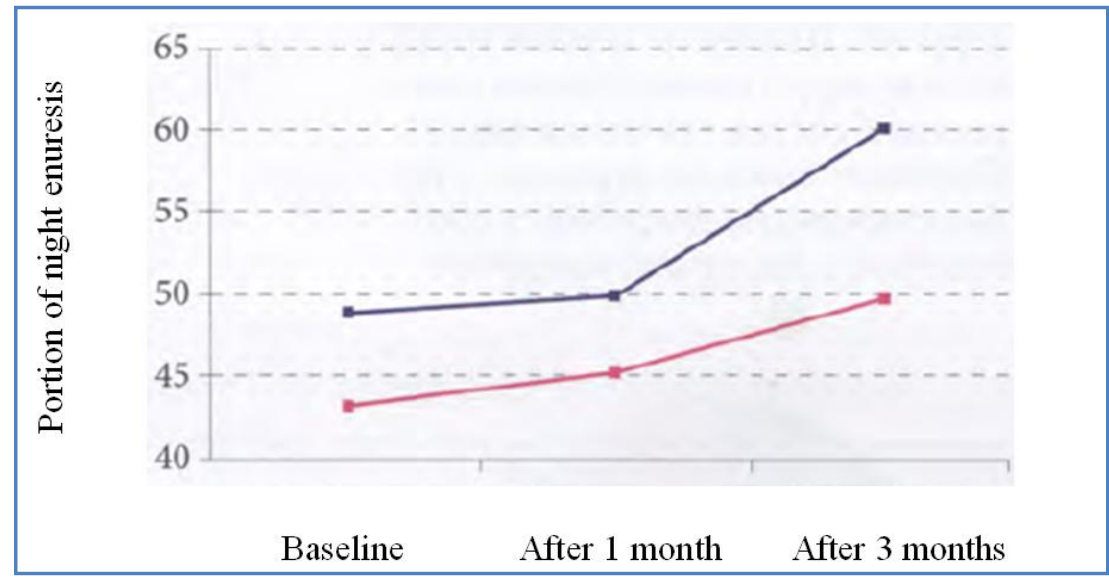

Figure 4 Dynamics of minimal voiding volume against the background of combined and basic therapy in children with OAB syndrome 
After 3 months of treatment, patients of this group on the base with oxybutynine therapy maximum bladder capacity increased by $28 \%$. Evaluation of clinical symptoms during this period has changed with respect to 1) urgency, 2) an imperative urinary incontinence and effective volume, but this difference did not reach statistical significance when compared with the initial value. In addition, the results compared with the results of Group 1 for the same period of treatment (Fig. 4). A more modest number of bedwetting episodes and did not change significantly in the persistent level of nocturnal polyuria remaining in the 2 nd group. In this case, the 17 children $(57 \%)$ the number of episodes of nocturnal enuresis decreased from 2 to 1 day. Kramer-Welch test was set for uniform groups studied parameters. Indeed, after the first month of therapy results were statistically indistinguishable $(\mathrm{p}$ $=0.049)$, but after three months difference reached statistical significance for parameters such as the volume $(\mathrm{p}=0.00088)$ and the number of nocturnal enuresis $(\mathrm{p}=0.000017)$ episodes (Warne et al., 2012).

In comparison to the results of the 1st group with the results of group 2, it was found that in the presence of an imperative sindromadroma and nocturnal polyuria best results were obtained with the integrated use of desmopressin MELT and oxybutynine. The main therapy in the form of oxybutynin increases bladder capacity by one-third, but as largely spontaneous bladder emptying occurs during nighttime urination, polyuria continuing to provoke uncontrolled emptying of the bladder at night. It does not improve a child's ability to hold urine. The uncontrolled long-term incontinence lowers self-esteem of the patient. Results of present study are in agreement with findings of the previous researchers (Abrams et al., 2003; Glazener \& Evans, 2002).

\section{Conclusion}

In a study of 150 children aged 5-17 years nocturia was identified with complaints of enuresis and imperative syndrome authors in $40 \%$ of patients. High incidence of nocturia children with the $\mathrm{OAB}$ syndrome required administration of desmopressin MELT combinedly with basic medicine to stabilize the detrusor: oxybutynine.

The use of desmopressin MELT require dose adjustment after 1 month of treatment in $1 / 4$ of cases in patients older than 12 years. Results of the combination therapy led to the achieve a statistically significant reduction in the number of urinary incontinence episodes per day and night time in 4-6 weeks from the beginning of treatment. In group of children who received only basic therapy oxybutynine this effect was not observed. The positive results obtained in the treatment of children in a combined way significantly increased the selfesteem of children and improve the quality of family life.

\section{Conflict of interest}

Authors would hereby like to declare that there is no conflict of interests that could possibly arise.

\section{Reference}

Abrams P, Blaivas JG, Fowler CJ, Fourcroy JL, Macdiarmid SA, Siegel SW, Van Kerrebroeck P (2003) The role of neuromodulation in the management of urinary urge incontinence. British Journal Urology International 91: 355359.

Bauer SB (2002) Special considerations of the overactive bladder in children. Urology- 60:43-48. DOI: http://dx.doi.org/10.1016/S0090-4295(02)01793-4.

Dreiper N, Smit G (2007) The practical regression analyses. The complicated regression, 2007: 912.

Glazener CM, Evans JH (2002) Desmopressin for nocturnal enuresis in children. Cochrane Database Systemic Review 3 :CD002112. DOI: 10.1002/14651858.CD002112.

Nijman RJ (2004) Role of antimuscarinics in the treatment of nonneurogenic daytime urinary incontinence in children. Urology 63: 45-50. http://dx.doi.org/10.1016/j.urology.2003.11.004.

Raes A, Dehoorne J, Hoebeke P, Van Laecke E, Donckerwolcke R, Vande Walle J (2006) Abnormal circadian rhythm of diuresis or nocturnal polyuria in a subgroup of children with enuresis and hypercalciuria is related to increased sodium retention during daytime. Journal of Urology 176:1147-1151. DOI: http://dx.doi.org/10.1016/j.juro.2006.04.054.

Sureshkumar P, Bower W, Craig JC, Knight JF (2003) Treatment of daytime urinary incontinence in children: a systematic review of randomized controlled trials. Journal of Urology 170:196-200. DOI: http://dx.doi.org/10.1097/01.ju.0000072341.34333.43.

Vishnevsky EL (2005) The children with overactive bladder. Abstracts of Russian Urological association. Tyumen city, Pp: 71-72.

Vishnevsky EL, Loran OB, Pushkar DY, Petrov SB (2007) Obstructive nocturia. Publisher: M .: ANMI, Pp. 162.

Visniewsky EL, Loran OB, Wisniewski AE (2001) Clinical evaluation of urinary disorders,: M TERRA, Pp. 96;

Warne RT, Lazo M, Ramos T, Ritter N (2012) Statistical methods used in gifted education journals, 2006-2010. Gifted Child Quarterly 56: 134-149. doi: $10.1177 / 0016986212444122$. 